água, arejamento e drenagem. É muito provável também que o uso da PN tenha prejudicado o desenvolvimento das mudas devido à deficiência de nitrogênio em decorrência à alta relação carbono:nitrogênio que a palha crua apresenta.

Estes resultados estão de acordo com os critérios de Klougart (1982), que conclui que o uso de soluções nutritivas pouco concentradas permite a obtenção de mudas de alta qualidade quando o substrato utilizado fornece condições físicas e químicas ideais.

Nas condições desse experimento, na escolha da muda com vigor na parte aérea e raiz e com boa porcentagem de sobrevivência, recomenda-se o substrato à base de terra ou também o substrato vermiculita e o uso de solução nutritiva para a produção de mudas de pepino japonês de alta qualidade.

\section{LITERATURA CITADA}

BALLARIN, J.T. Relatório final da residencia. Botucatu: UNESP-FCA, 1996, 40 p. (Relatório). BARROS, S.B.M. Avaliação de diferentes recipientes na produção de mudas de tomate (Lycopersicum esculentum Mill) e pepino (Cucumis sativus L.) Piracicaba, 1997. 70 p. (Dissertação Mestrado). ESALQ.

CAÑIZARES, K.A L.; IOZI, R.N; STRIPARI, P.C.; GOTO, R. Enxertado, japonês fica mais brilhante. Agrianual 97. Anuário Estatístico da Agricultura Brasileira. FNP, Consultoria \& Comércio, 1996. p. 332-33.
KLOUGART, A. Substrates and nutrient flow. Acta Horticulturae, v. 150, p. 296-313, 1982.

MINAMI, K. Produção de mudas de alta qualidade em horticultura. Campinas: Fundação Farah Maluf, 1995. 128 p.

SARRUGE, J.R. Soluções nutritivas. Summa Phytopatologica, v. 1, p. 231-3, 1975.

TAVEIRA. J.A.M. Produção de mudas em containers. 1994.9 p. (mimeografado).

TESSARIOLI NETO, J. Recipientes, embalagens e acondicionamento de mudas de hortaliças. In: MINAMI, K.; GONÇALVES, A.L.; PENTEADO, S.R.; SCARPARE FILHO, J.A.; SILVEIRA, R.B.A. Produção de mudas de alta qualidade em horticultura. São Paulo: Fundação Salim Farah Maluf, 1995. p. 59-64.

YURI, J.E.; SOUZA, R.J.; FREITAS, S.A.C. RODRIGUES JÚNIOR, J.C.; MOTA, J.H. Comportamento de cultivares de alface tipo americana em Boa Esperança. Horticultura Brasileira, Brasília, v. 20, n. 2, p. 229-232, junho, 2.002.

\title{
Comportamento de cultivares de alface tipo americana em Boa Esperança ${ }^{1}$
}

\author{
Jony E. Yuri ${ }^{2}$, Rovilson J. de Souza ${ }^{2}$; Silvio A.C. de Freitas ${ }^{3}$; Juarez C. Rodrigues Júnior ${ }^{3}$; \\ José Hortêncio Mota ${ }^{2}$ \\ ${ }^{2}$ UFLA, C. Postal 37, 37.200-000 Lavras - MG. ${ }^{3}$ REFRICON, Rod. Regis Bittencourt s/n km 294, 06.850-000 Itapecerica da Serra-SP; \\ E.mail: jony@ufla.br
}

\section{RESUMO}

Os experimentos foram conduzidos em estufas (túnel alto) no município de Boa Esperança (MG), para avaliar cultivares de alface do grupo americana ("Crisphead lettuce”), em duas épocas de plantio (outubro e março). As cultivares (Cassino; Legacy; Lucy Brown; Lorca; Lady e Raider) foram plantadas em delineamento de blocos casualizados com quatro repetições. Para a primeira época (outubro), a produção comercial variou de 29,3 t.ha ${ }^{-1}$ a 37,6 tha ${ }^{-1}$ e circunferência da cabeça de 40,07 a 42,95 cm, não apresentando diferenças significativas entre cultivares. Na segunda época de plantio (março), sobressaíram-se as cultivares Raider, Cassino, Lady, Legacy e Lorca com produção comercial de 42,6; 41,6; 39,3; 37,3 e 32,5 t.ha ${ }^{-1}$, respectivamente. Quanto à circunferência de cabeça comercial, as cultivares Lady, Raider, Lucy Brown e Cassino, foram superiores às demais cultivares, com 48,15; 46,69; 45,90 e 45,67 cm respectivamente, sem diferirem significativamente entre si.

Palavras-chaves: Lactuca sativa L., cultivo protegido, competição.

\begin{abstract}
Performance of crisphead lettuce cultivars in Boa Esperança, Brazil

The experiment was carried out at green house, in Boa Esperança, Brazil, to evaluate lettuce cultivars (Cassino; Legacy; Lucy Brown; Lorca; Lady and Raider), crisphead group, in two planting seasons (October and March). The experimental design was of randomized blocks with four replications. For the first season (October), the commercial yield, varied from 29.3 t.ha $^{-1}$ to 37.6 t.ha $^{-1}$ and head circumference from 40.07 to $42.95 \mathrm{~cm}$, without significant difference among cultivars. At the second planting season (March), cvs. Raider, Cassino, Lady, Legacy and Lorca presented a commercial yield of 42.6; 41.6; 39.3; 37.3 and 32.5 t.ha ${ }^{-1}$. Cvs. Lady, Raider Lucy Brown and Cassino, were superior to the other cultivars, without significant differences among themselves, with $48.15 ; 46.69 ; 45.90$; and 45.67 $\mathrm{cm}$ respectively.
\end{abstract}

Keywords: Lactuca sativa L., protect cultivation, competition.

\section{(Aceito para publicação em 17 de dezembro de 2.001)}

$\mathrm{N}$ o Brasil, a alface é a hortaliça folhosa de maior aceitação pelo consumidor. Apresentando elevados teores de vitaminas e de sais minerais, indispensáveis na dieta alimentar, além de possuir baixo teor de calorias, aconselhável nas dietas por ser de fácil diges- tão. Atualmente a produção nacional é de 260.000 toneladas por ano; a região Sudeste é responsável por $70 \%$ dessa produção (IBGE, 1996a, 1996b).

O desenvolvimento da alface é bastante influenciada pelas condições ambientais. Temperaturas acima de $20^{\circ} \mathrm{C}$ estimulam o seu pendoamento, que é acelerado à medida que a temperatura aumenta. Dias longos associados a temperaturas elevadas, aceleram ainda mais o pendoamento, mas há variação de comportamento entre cultivares (Viggiano, 1990). O melhor desenvol-

\footnotetext{
${ }^{1}$ Parte do trabalho para elaboração da dissertação de mestrado em Agronomia, área de concentração em Fitotecnia pela UFLA, MG.
} 
vimento tem sido observado em temperaturas oscilando entre 15 e $20^{\circ} \mathrm{C}$ (Lenano, 1973; Brunini et al., 1976; Cásseres, 1980).

Em se tratando da alface americana, Sanders (1999) afirma que ela é adaptada à temperatura amena, tendo como ótima a faixa entre 15,5 e $18,3^{\circ} \mathrm{C}$. Entre 21,1 e $26,6^{\circ} \mathrm{C}$ a planta floresce e produz sementes, podendo tolerar alguns dias com temperaturas de 26,6 a $29,4^{\circ} \mathrm{C}$, desde que as temperaturas noturnas sejam baixas. Segundo Jackson et al. (1999), a alface Americana requer, como temperatura ideal para o desenvolvimento, $23^{\circ} \mathrm{C}$ durante o dia e $7^{\circ} \mathrm{C}$ à noite. Temperaturas muito elevadas podem provocar queima das bordas das folhas externas, formar cabeças pouco compactas e também contribuir para ocorrer deficiência de cálcio, conhecida como "tipburn". Baixas temperaturas, próximas do congelamento, não provocam danos em plantas jovens, porém o seu desenvolvimento é retardado. Essas condições, no entanto, podem prejudicar plantas próximo ao ponto de colheita, danificando as folhas externas.

Outro fator que pode afetar a planta é o fotoperíodo, pois a alface exige dias curtos para se manter na fase vegetativa e, dias longos, para que ocorra o pendoamento (Robinson et al., 1983). Combinando fotoperíodos e temperaturas no cultivo de vários genótipos de alface, Waycott (1995) mostrou que a temperatura isoladamente não induziu a alface ao pendoamento, ao contrário do fotoperíodo. Concluiu também que existe resposta diferenciada dos genótipos ao comprimento de dia. Segundo Conti (1994), as cultivares européias importadas já estão adaptadas a dias mais longos do que os que ocorrem no Brasil.

Nas condições de Lavras (MG), em altitude de 918 metros, Bueno (1998) verificou que a cultivar Lorca, plantada em junho teve peso médio de $801 \mathrm{~g}$ por planta. Com a mesma cultivar, época de plantio e local, Mota (1999) obteve peso médio por planta de $1056 \mathrm{~g}$. Alvarenga (1999), com plantio em maio, da cultivar Raider em Santo Antônio do Amparo (MG), a uma altitude de $1050 \mathrm{~m}$, atingiu um peso médio por planta de 1000 g. Em Campinas, Bernardi \& Igue
(1973), verificaram que as cultivares Great Lakes e New York, ambas pertencentes ao grupo Americana, foram mais produtivas em ensaio de competição entre cultivares, apresentando, em média, 644 e 610 g por planta, sendo que as maiores, chegaram a $1.050 \mathrm{e}$ $1.000 \mathrm{~g}$, respectivamente. Avaliando o comportamento de cultivares de alface de diferentes grupos na região Serrana do Estado do Rio de Janeiro, durante o verão, Leal et al. (1974) verificaram que a cultivar Mesa 659, do grupo americana, foi a que apresentou melhor formação de cabeça, com 57,9\% das plantas apresentando peso superior a $400 \mathrm{~g}$.

O presente trabalho objetivou avaliar o comportamento de cultivares de alface americana em duas épocas de cultivo, no município de Boa Esperança (MG).

\section{MATERIAL E MÉTODOS}

O experimento foi conduzido no município de Boa Esperança, região Sul de Minas Gerais, a uma altitude de 800 metros, situado a $21^{\circ} 05^{\prime} 15^{\prime \prime}$ de latitude Sul e 45 34'00" de longitude Oeste, em solo classificado como Latossolo Vermelho Distrófico (LVd).

O delineamento experimental utilizado foi blocos casualizados, com 4 repetições, sendo os tratamentos constituídos por seis cultivares de alface americana (Cassino, Legacy, Lucy Brown, Lorca, Lady e Raider). O primeiro experimento foi realizado de setembro a dezembro/98, com transplantio efetuado aos 30 dias após o plantio (DAP). O segundo de fevereiro a maio/99, com o transplantio aos 30 DAP.

A semeadura foi realizada 30 dias antes do transplante, em bandejas de isopor contendo 200 células. Foi utilizado o substrato comercial Plantmax HT da Eucatex.

Com base nas análises de solo, a área experimental utilizada na primeira época foi corrigida com calcário dolomítico. A adubação de base foi feita dois dias antes do transplantio, utilizando-se uma mistura de adubo formulado 4-30-16 com o termofosfato magnesiano Yoorim Master, em que se aplicou 37,5 kg.ha-1 de $\mathrm{N}$; 600 kg.ha ${ }^{-1}$ de $\mathrm{P}_{2} \mathrm{O}_{5}$ e 150 kg.ha ${ }^{-1}$ de $\mathrm{K}_{2} \mathrm{O}$. Na a segunda época foi aplicado $400 \mathrm{~kg} \cdot \mathrm{ha}^{-1}$ de $\mathrm{P}_{2} \mathrm{O}_{5}$ e as mesmas do- ses de $\mathrm{N} \mathrm{e}_{2} \mathrm{O}$ utilizados anteriormente.

Os canteiros foram construídos com 45 metros de comprimento e 1,20 metro de largura. Em cada par de canteiros foi instalada uma estrutura de proteção, constituída de túnel alto, com $3 \mathrm{~m}$ de largura e 1,70 m de altura, coberto com filme plástico transparente de baixa densidade, aditivado com anti-UV, de 75 micras de espessura. $\mathrm{Na}$ área central de cada canteiro foram demarcadas 3 parcelas, ou seja, seis em cada estrutura de túnel alto, onde os tratamentos foram distribuídos de modo aleatório. Cada parcela mediu 4 metros de comprimento por 1,2 metro de largura, onde foram plantadas 4 linhas de alface espaçadas entre si de $35 \mathrm{~cm}$, sobrando uma margem de 7,5 cm em cada lateral do canteiro. Dentro de cada linha de plantio, o espaçamento foi de $35 \mathrm{~cm}$, totalizando assim 46 plantas por parcela. A área útil da parcela foi formada por 20 plantas das duas linhas centrais do canteiro.

O sistema de irrigação utilizado durante a primeira semana da cultura no campo foi por aspersão e posteriormente por gotejamento. Este consistiu de duas linhas de tubo gotejador "Streamline 6000", com vazão de 1,2 litros. $\mathrm{h}^{-1}$ por emissor. Após a instalação dos tubos gotejadores, os canteiros foram cobertos por um filme plástico preto ("mulching"), com a finalidade de evitar a infestação de plantas daninhas e o contato da alface com o solo.

O controle de doenças e pragas na primeira época foi realizado com pulverizações semanais com produtos à base de cobre e com inseticida piretróide (Decis $25 \mathrm{CE}$ ). Na segunda época, as pulverizações, com os mesmos produtos foram realizadas a cada 15 dias, pois as condições climáticas foram menos favoráveis a pragas e doenças.

Para o controle das plantas daninhas, utilizou-se, a capina manual em torno das covas e o herbicida de contato paraquat entre os canteiros, com pulverizador costal com bico especial para evitar a deriva do produto para as plantas de alface.

Uma semana após o transplantio, teve início a adubação de cobertura realizada por fertirrigação, utilizando-se os adubos solúveis nitrato de potássio, nitrato de cálcio, sulfato de magnésio e 
Comportamento de cultivares de alface tipo americana em Boa Esperança.

Tabela 1. Produção total e produção comercial das cultivares de alface americana em duas épocas de plantio. Boa Esperança, UFLA, $1998 / 99$.

\begin{tabular}{|c|c|c|c|c|}
\hline \multirow{2}{*}{ Cultivar } & \multicolumn{2}{|c|}{ Produção total (t.ha ${ }^{-1}$ ) } & \multicolumn{2}{|c|}{ Produção comercial (t.ha-1) } \\
\hline & $1^{a}$ Época * & $2^{\text {a }}$ Época ** & $1^{\text {a Época * }}$ & $2^{\mathrm{a}}$ Época ** \\
\hline Cassino & $42,8 \quad b$ & 52,5 & 29,3 & $41,6 a$ \\
\hline Legacy & $49,1 \mathrm{ab}$ & 52,2 & 35,2 & $37,3 \mathrm{ab}$ \\
\hline Lucy Brown & 58,3 a & 48,2 & 37,6 & $28,9 \quad b$ \\
\hline Lorca & $48,1 \mathrm{ab}$ & 47,5 & 32,4 & $32,5 \mathrm{ab}$ \\
\hline Lady & $47,3 \quad b$ & 59,5 & 35,8 & $39,3 \mathrm{ab}$ \\
\hline Raider & $41,5 \quad b$ & 57,3 & 31,0 & $42,6 \mathrm{a}$ \\
\hline C.V.(\%) & 9,56 & 10,91 & 13,62 & 12,69 \\
\hline
\end{tabular}

Médias seguidas por letras minúsculas iguais nas colunas não diferem entre si a 5\% de probabilidade pelo Teste de Tukey.

* $1^{\circ}$ época: colheita em dezembro/98; ** $2^{\circ}$ época: colheita em março/99.

Tabela 2. Circunferência de cabeça e comprimento de caule de cultivares de alface americana duas épocas de plantio. Boa Esperança, UFLA, 1998/99.

\begin{tabular}{|c|c|c|c|c|}
\hline \multirow{2}{*}{ Cultivar } & \multicolumn{2}{|c|}{ Circunfer. cabeça $(\mathrm{cm})$} & \multicolumn{2}{|c|}{ Comprimento caule (cm) } \\
\hline & $1^{a}$ Época * & $2^{\text {a Época ** }}$ & $1^{\text {a Época * }}$ & $2^{\text {a Época ** }}$ \\
\hline Cassino & 40,40 & $45,67 a b$ & $5,42 \mathrm{a}$ & 3,32 \\
\hline Legacy & 40,07 & $41,70 \quad c$ & $4,32 \mathrm{ab}$ & 3,72 \\
\hline Lucy Brown & 41,95 & $45,90 a b$ & $3,72 \mathrm{bc}$ & 3,02 \\
\hline Lorca & 42,95 & $43,07 \quad b c$ & 2,92 & 2,82 \\
\hline Lady & 41,10 & 48,15 a & 2,70 & 3,12 \\
\hline Raider & 40,97 & $46,60 \mathrm{ab}$ & $2,72 \quad c$ & 3,32 \\
\hline C.V.(\%) & 3,87 & 3,49 & 14,21 & 14,11 \\
\hline
\end{tabular}

Médias seguidas por letras minúsculas iguais nas colunas não diferem entre si a 5\% de probabilidade pelo Teste de Tukey.

* $1^{\circ}$ época: colheita em dezembro/98; ** $2^{\circ}$ época: colheita em março/99.

cloreto de potássio, na dose de $40 \mathrm{~kg} \cdot \mathrm{ha}^{-1}$ de N; 80 kg.ha ${ }^{-1}$ de $\mathrm{K}_{2} \mathrm{O}$ e $50 \mathrm{~kg} \cdot \mathrm{ha}^{-1}$ de $\mathrm{Ca}$, aplicados diariamente. A fertirrigação foi feita até dois dias antes da colheita.

A colheita foi efetuada quando as cultivares apresentavam o máximo crescimento vegetativo, com cabeças bem compactas e grandes. Ela consistiu do corte da planta logo abaixo das folhas basais, rente ao solo. Foram avaliadas a produção total e comercial; circunferência da cabeça comercial; e comprimento do caule.

Para obtenção da produção total e comercial, as 20 plantas colhidas na área útil foram pesadas com as folhas externas (produção total) e sem as folhas externas (produção comercial) e, posteriormente extrapoladas para um hectare, com 60.000 plantas, baseado no espaçamento de $35 \mathrm{~cm} \times 35 \mathrm{~cm}$, e também no espaçamento entre canteiros de $60 \mathrm{~cm}$ (para circulação). Após a pesa- gem, efetuou-se a medida da sua circunferência. Em seguida foi medido o comprimento de caule retirando-se as folhas.

Os dados obtidos em cada época de plantio foram submetidos à análise de variância sendo que as médias foram comparadas pelo teste de Tukey.

\section{RESULTADOS E DISCUSSÃO}

Para a produção total na primeira época, sobressaíram-se as cultivares Lucy Brown (58,3 t.ha-1), Legacy (49,1 t.ha-1) e Lorca $\left(48,1\right.$ t.ha $\left.^{-1}\right)$, com peso médio por planta de 972; 818 e $801 \mathrm{~g}$, respectivamente. Mota (1999) obteve com a cultivar Lorca, um rendimento superior $(63,3$ t.ha-1 $)$, nas condições de Lavras.

Para a segunda época de plantio, com semeadura em fevereiro, não houve diferença significativa entre as cultivares avaliadas, tendo a produção total variado de 47,5 a 59,5 t.ha-1 (Tabela 1).
Esses resultados são semelhantes ao obtido por Bueno (1998), que obteve para cultivar Lorca, com semeadura em março, a produção total de 48,0 t.ha-1 .

A análise de variância da produção comercial de alface na primeira época de plantio, não mostrou diferença significativa entre as cultivares, apresentando variação entre 29,3 e 37,6 t.ha $^{-1}$ (Tabela 1). Para a segunda época, as cultivares Raider, Cassino, Lady , Legacy e Lorca apresentaram os maiores rendimentos, variando de 32,5 a 42,6 t.ha ${ }^{-1}$, respectivamente.

Observa-se na Tabela 2 que na primeira época de plantio não houve diferença significativa entre as cultivares para circunferência da cabeça, que variou de 40,07 a 42,95 cm. Para a segunda época de plantio destacaram-se as cultivares Lady, Raider, Cassino e Lucy Brown que apresentaram circunferência de cabeça variando de 45,67 a 48,15 cm. Resultados semelhantes foram obtidos 
por Bueno (1998) que relatou uma circunferência de $44,98 \mathrm{~cm}$, e por Mota (1999), que verificou uma circunferência de $46,51 \mathrm{~cm}$, para a cultivar Lorca, ambos com semeadura em março, nas condições de Lavras, MG.

$\mathrm{Na}$ primeira época de plantio foi verificado que as cultivares Lady, Raider, Lorca e Lucy Brown apresentaram os menores comprimentos de caule, de 2,70 a 3,72 cm (Tabela 2). Dentre as características desejáveis de uma cultivar, tem importância o comprimento de caule, pois cultivar com caule excessivamente comprido não apresenta boa compacidade e dificulta o beneficiamento da mesma, afetando a qualidade final do produto. Na segunda época de plantio, não houve diferença significativa entre as cultivares, que apresentaram comprimento médio de caule por planta variando de 2,82 a 3,72 cm (Tabela 2). Bueno (1998) em Lavras, estudando a cultivar Lorca, com semeadura em março, verificou que o comprimento de caule variou de 5,6 a 6,8 $\mathrm{cm}$, bem acima dos valores obtidos neste trabalho, provavelmente pelo fato desse experimento ter sido conduzido em estufa fechada e com pé-direito de 2,0 $\mathrm{m}$, provocando assim aumento excessivo da temperatura.

Com base nos resultados obtidos no presente trabalho, verificamos a possibilidade de se utilizar as cultivares Lady,
Raider, Lorca Lucy Brown e Legacy durante a primeira época de plantio, por apresentarem comprimento de caule menores, enquanto para a segunda época de plantio, indicam-se as cultivares: Raider, Lady e Cassino, por apresentarem maiores produtividade e circunferência da cabeça comercial.

\section{LITERATURA CITADA}

ALVARENGA, M.A.R. Crescimento, teor $e$ acúmulo de nutrientes em alface americana (Lactuca sativa $L$.) sob doses de $N$ aplicadas no solo e de níveis de cálcio aplicados via foliar. Lavras: UFLA, 1999. 117 p. (Tese doutorado)

BERNARDI, J.B.; IGUE, T. Comportamento de cultivares de alface na região de Campinas. VI. Cultura de Setembro a Novembro de 1972. Revista de Olericultura, Campinas, v. 13, p. 29-31, 1973. BRUNINI, O.; LISBÃO, R.S.; BERNARDINI, J.B.; FORNASIER, J.B.; PEDRO Jr., M.J. Temperaturas básicas para alface, cultivar White Boston, em sistemas de unidades térmicas. Bragantia, Campinas, v. 19, n. 35: p. 213-219, 1976.

BUENO, C.R. Efeito da adubação nitrogenada em cobertura via fertirrigação por gotejamento para a cultura da alface tipo americana em ambiente protegido. Lavras: UFLA,1998. 54 p. (Tese mestrado).

CÁSSERES, E. Produccion de hortalizas. São José - Costa Rica: Instituto Interamericano de Ciências Agrícolas, 1980. 387 p.

CONTI, J.H. Caracterização de cultivares de alface (Lactuca sativa L.) adaptadas aos cultivos de inverno e verão. Piracicaba: ESALQ, 1994. (Tese mestrado)

IBGE. Censo agropecuário: Brasil. Rio de Janeiro, 1996a. Disponível: http:// www.sidra.ibge.gov.br/download/f5756.csv. Consultado em 24 out. 1999.
IBGE. Censo agropecuário: Sudeste. Rio de Janeiro, 1996b. Disponível: http:// www.sidra.ibge.gov.br/download/f5756.csv. Consultado em 24 out. 1999.

JACKSON, L.; MAYBERRY, K.; LAEMMLEN, F.; KOIKE, S.; SCHLUBACK, K. Iceberg lettuce production in California: disponível: http// www.vegetablecrops.ucdavis. Consultado em 24 out. 1999.

LEAL, N.R.; LIBERAL, M.T.; COELHO, R.G. Comportamento de cultivares de alface (Lactuca sativa L.) na região serrana do Estado do Rio de Janeiro. Revista Ceres, Viçosa, v. 21, n. 118, p. 506-509, 1974.

LENANO, F. Como se cultivam las hortalizas do hojas. Barcelona: Editorial Vecchi, 1973. 228 p.

MOTA, J.H. Efeito do cloreto de potássio via fertirrigação na produção de alface americana em cultivo protegido. Lavras:UFLA, 1999. 46 p. (Tese mestrado)

PIZARRO, F. Riegos localizados de alta frecuencia. Madrid, Espanha: Mundi-Prenza, 1987. $416 \mathrm{p}$

ROBINSON, R.W.; McCREIGT, J.D.; RYDER, J.E. The genes of lettuce and closely related species. In: JANICK, J. (ed.) Plant breeding reviews. Westport: AVI, 1983, v. 1, 397 p.

SANDERS, D.C. Lettuce production: Disponível: http//www.ces.ncsu.edu/depts/hort/hil/hil-11.html. Consultado em 11 out. 1999.

THOMPSON, C.; BEST, K. Lettuce observational trial 1992: Available: http://agri.gov.ns.ca/pt/ projsum/92/lettuce.html. Consultado em 2 nov. 1999

VIGGIANO, J. Produção de sementes de alface. In: CASTELLANE, P.D. (org.) Produção de sementes de Hortaliças. Jaboticabal: FCAV/FUNEP, 1990. p. 1-15.

WAYCOTT, W. Photoperiodic response of genetically diverse lettuce accessions. Journal of American Society for Horticultural Science, v. 120, n. 3, p. 460-467, 1995. 